\title{
ELECTRON MICROSCOPIC DEMONSTRATION OF HORSERADISH PEROXIDASE-TETRAMETHYLBENZIDINE REACTION PRODUCT AS A METHOD FOR IDENTIFYING SENSORY NERVE FIBERS IN THE RAT TOOTH PULP
}

\author{
DENNIS F. TURNER' and CARL F. MARFURT ${ }^{2}$ \\ 'Department of Oral' Biology, University of Michigan Dental School, Ann Arbor, MI 48109 and \\ 'Department of Anatomy. The Milton S. Hershey Medical Center, The Fennsylvania State LIniversity. \\ Hershey, PA 17033 (U.S.A)
}

(Received July 26th, 1983; Accepted August 29th, 1983)

Key words: horseradish peroxidase - electron microscopy - tooth pulp - sensory nerve endings

The purpose of the present investigation was to determine if the horseradish peroxidase (HRP) technique could be used as a method for labeling sensory nerve fibers (specifically, tooth pulp afferents) for detailed ultrastructural analyses. HRP injected into the trigeminal ganglion of adult rats was taken up by ganglion cell bodies and transported anterogradely to their per pheral endings in the dental tissues. Following perfusion-fixation, the teeth were decalcified in EDTA, sectioned, reacted for HRP activity according to the tetramethylbenzidine (TMB) technique, and processed for electron microscopy. The HRP-TMB reaction product was clearly visible within most of the axons in the dental pulp, appearing as conspicuous, rectangular shaped aggregates of fine rods or needles.

Considerable research has been directed in recent years towards the succesful identification and morphological analysis of sensory nerve fibers in the dental pulp organ $[1-4,7]$. Detailed information concerning the morphology and mode of termination of these fibers is of great interest because the majority (if not all) of the fibers are thought to be nociceptive in nature. Unfortunately, the ability to identify neural elements in the dental pulp organ and to trace them successfully to their ultimate sites of termination has been hampered in previous ultrastructural studies due to the extremely small size of the nerve fibers and the apparent lack within the pulpal nerve endings of specific organelles (i.e. mitochondria, synaptic vesicles) that are characteristic of axonal terminals in other sensory systems. Recently, Byers and coworkers $[3,4]$ have reported that they can facilitate greatly the light and electron microscopic identification of these extremely fine diameter sensory fibers by labeling them intraaxonally with radioactive compounds. Similarly, we have demonstrated that the enzyme horseradish peroxidase (HRP), can also be used as an anterograde tracer substance for labeling sensory nerve endings in dental, and other tissues 


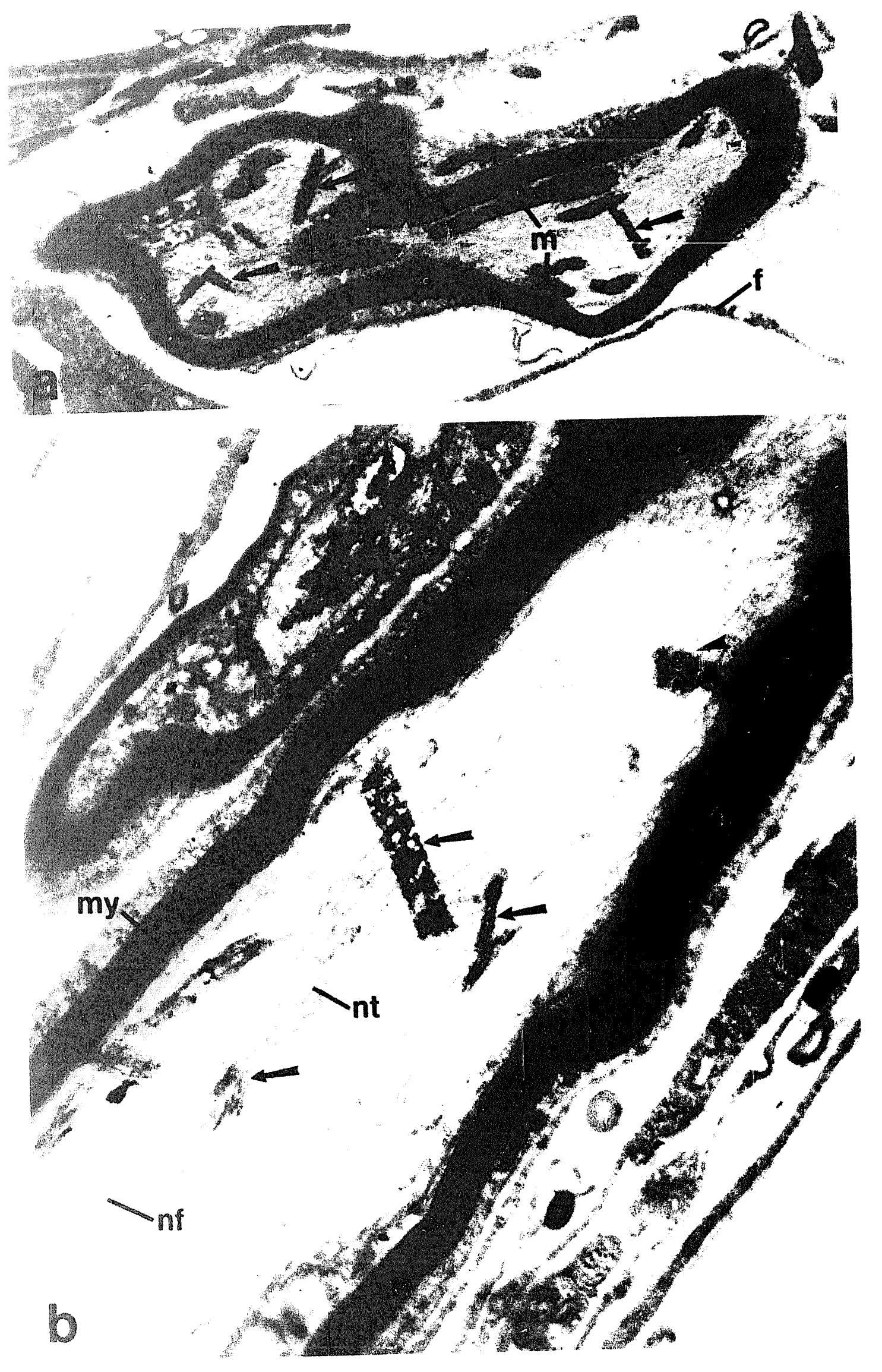


[8]. The purpose of the current report is to document the successful extension of our previous light microscopic studies to the ultrastructural level.

Four adult Sprague-Dawley rats of either sex, weighing $200-400 \mathrm{~g}$, were used in the present study. The surgical procedures, postoperative survival times, and perfusion techniques used were the same as those described by Marfurt and Turner [8]. Briefly, the left trigeminal ganglion of each animal was exposed on the floor of the middle cranial fossa by removing a small portion of the parietal bone and aspirating the underlying brain tissue. At each of one to three sites along the ganglion, 0.5-2.0 $\mu \mathrm{l}$ of $30 \%$ HRP (Sigma type VI) in saline was injected using a glass micropipette, tip diameter $50-70 \mu \mathrm{m}$. The animals were sacrificed $24 \mathrm{~h}$ postinjection via perfusionfixation through the left ventricle with $200 \mathrm{ml}$ of warm heparinized saline, followed by $500 \mathrm{ml}$ of $4 \%$ glutaraldehyde- $1 \%$ paraformaldehyde in $0.1 \mathrm{M}$ phosphate buffer, $\mathrm{pH} 7.4$, for $15-30 \mathrm{~min}$. This was followed by an additional 15-30 min flush with $500 \mathrm{ml}$ of cold $\left(4^{\circ} \mathrm{C}\right) 0.1 \mathrm{M}$ phosphate buffer containing $10 \%$ sucrose.

Immediately following the perfusion, those portions of the ipsilateral maxilla and mandible containing the 3 molar teeth were removed and decalcified over a period of 2-3 weeks in daily changes of buffered $0.2 \mathrm{M}$ sodium (tetra)ethylene diamine tetraacetate (EDTA) at pH 7.4. Most blocks of decalcified tissue, each consisting of a single molar tooth and its surrounding alveolar bone, were sectioned serially at $30-40 \mu \mathrm{m}$ in a cryostat. Efforts to section some blocks on a vibratome or TC-2 tissue chopper were less satisfactory due to the resiliency of the decalcified tissue, resulting in frequent variability in section thickness. The sections were then processed for the electron microscopic demonstration of HRP-TMB reaction product according to the methods of Carson and Mesulam [5] and others [11-13]. Briefly, this procedure consists of washing the tissue sections for $1 \mathrm{~min}$ each in 3 changes of room temperature distilled water, incubating in $100 \mathrm{ml}$ of TMB-sodium nitroprusside medium without $\mathrm{H}_{2} \mathrm{O}_{2}$ for $20 \mathrm{~min}$, then incubating in the same medium for an additional $10 \mathrm{~min}$ following the introduction of $3 \mathrm{ml}$ of $0.3 \% \mathrm{H}_{2} \mathrm{O}_{2}$. After incubation, the sections were washed in 3 changes of cold $5 \%$ acetate buffer for 1 min each, osmicated for $45 \mathrm{~min}$ in $1 \% \mathrm{OsO}_{4}$ in $0.1 \mathrm{M}$ phosphate buffer, $\mathrm{pH}$ 6.0 , at $45^{\circ} \mathrm{C}$, dehydrated for $7 \mathrm{~min}$ each in a series of graded alcohols, and flat

Fig. 1. Examples of HRP-TMB reaction product contained within tooth pulp axons of a rat first mandibular molar tooth. a: an isolated myelinated fiber containing numerous aggregates of reaction product (arrows). Note the characteristic high density and rod-like shape of the reaction product crystals, making them readily discernible from other axoplasmic organelles, such as mitochondria $(m)$. f, fibroblast, unstained $\times 18,500$. b: higher magnification of an obliquely-sectioned, HRP-labeled axon. At this magnification it can be seen that the reaction product granules (arrows) appear as stacks of needle-like crystals. Occasional deposits of reaction product that form near the edg $f$ the axoplasm may extend beyond the confines of the axon proper (arrowhead). Despite subjection of . :issue to the rather harsh incubation parameters used in HRP neurohistochemistry, the morphological preservation is well within acceptable levels. $n t$, neurotubules; nf, neurofilaments; my, myelin. unstained $\times 87,500$. (Figure reduced by $27 \%$ in production.) 
embedded in Spurrs epoxy resin between two Teflon-coated coverslips [6, 10]. Following polymerization, the 80-100 $\mu \mathrm{m}$ thick resin wafers were examined in an Olympus light microscope and areas containing visible HRP-TMB reaction product were trimmed from the wafers and glued with quick-setting epoxy to the end of an epoxy resin block. Thin $(80-100 \mu \mathrm{m})$ sections were cut with a diamond knife on a Sorvall MT-2 ultramicrotome, collected on 150 mesh copper grids, and viewed, unstained, in a Philips 300 electron microscope.

HRP-TMB reaction product was identified readily within the majority of neural elements in the dental pulp organ of all animals examined. Most of the deposits of reaction product were rectangular in shape and appeared as crystal-like aggregates of fine rods or needles (Fig. 1). The unique structure of the reaction product made it easy to identify and we never encountered any difficulty in distinguishing these deposits from cellular organelles or inclusions. Most of the reaction product bundles were confined exclusively to axons, but occasionally some large granules penetrated the axolemma and extended in part into adjacent structures, e.g. myelin sheaths.

The present study has demonstrated for the first time the feasibility of using the HRP anterograde transport technique for the identification and detailed ultrastructural examination of sensory nerve fibers. Data generated from the present work have extended previous light microscopic observations [8, 9] to reveal that: (1) sufficient HRP is transported into the peripheral nerve fibers to make electron microscopic analysis feasible; (2) the HRP enzyme will survive the decalcification procedure described here in quantities sufficient enough to catalyze the oxidation of a suitable chromagen, i.e. TMB; (3) the unique, highly visible intracellular marker obtained by osmification of the HRP-TMB reaction product appears identical to that described by others in studies restricted to CNS tissue; and (4) ultrastructural morphology is maintained at an acceptable level, despite the rather lengthy decalcification time required and the necessity of employing frozen sections.

In conciusion, these results document a powerful new method for studying in detail the morphology, distribution, and mode of termination of sensory nerve fibers of known origin at the ultrastructural level. Although the present study confines itself to an examination of tooth pulp afferents, the technique should have widespread application to the study of other populations of trigeminal sensory nerve fibers or of spinal afferents [9]. We feel that by varying the site of enzyme application (e.g. sensory ganglion, autonomic ganglion, brainstem or spinal motor nuclei), this method of 'tagging' neural elements with a highly visible, readily distinguishable intracellular marker may be used to study the fine structure and anatomical relationships of highly select populations of nerve fibers of known sensory or motor origin.

D.F.T. was supported in part by Grants DE05255 and DE06585 and C.F.M. was supported in part by Grant DE609301. 
1 Avery, J.K., Cox, C.F. and Chiego, D.J., Jr., Presence and location of adrenergic nerve endings in the dental pulps of mice, Anat. Rec., 198 (1980) 59-71.

2 Bueltman, K.W., Karlsson, U.L. and Edie, J., Quantitative ultrastructure of intradental nerve fibers in marmosets, Arch. Oral Biol., 17 (1972) 645-660.

3 Byers, M.R., Large and small trigeminal nerve endings and their associations with odontoblasts in rat molar dentin and pulp, Advanc. Pain Res. Ther., 3 (1979) 265-270.

4 Byers, M.R. and Matthews, B., Autoradiographic demonstration of ipsilateral and contralateral sensory nerve endings in cat dentin, pulp, and periodontium, Anat. Rec., 201 (1981) 249-260.

5 Carson, K.A. and Mesulam, M.M., Electron microscopic demonstration of neural connections using horseradish peroxidase: a comparison of the tetramethylbenzidine procedure with seven other histochemical methods. J. Histochem. Cytochem., 30 (1982) 425-435.

6 Cheng, J.P., A new technique for separation of coverglass substrate from epoxy-embedded specimens for electron microscopy, J. Ultrastruct. Res., 37 (1971) 370-377.

7 Johnsen, D.C. and John, S., Quantitation of nerve fibers in the primary and permanent canine and incisor teeth in man, Arch. Oral Biol., 19 (1974) 671-678.

8 Marfurt, C.F. and Turner, D.F., Sensory nerve endings in the rat oro-facial region labeled by the anterograde and transganglionic transport of horseradish peroxidase: a new method for tracing peripheral nerve fibers, Brain Res., 261 (1983) 1-12.

9 Robertson, B. and Aldskogius, H., The use of anterogradely transported wheat germ agglutinhorseradish peroxidase conjugate to visualize cutaneous sensory nerve endings, Brain Res., 240 (1982) 327-330.

10 Romanowicz, D.K. and Hanker, J.S., Wafer en bedding: specimen selection in electron microscopic cytochemistry with osmiophilic polymers, Histochem. J., 9 (1977) 317-327.

11 Sakumoto, T., Nagal, T., Kimura H. and Maeda, T., Electron microscopic visualization of tetramethylbenzidine reaction product on horseradish peroxidases neurohistochemistry, Cell. molec. Biol., 26 (1980) 211-216.

12 Schonitzer, K. and Hollander, H., Anterograde tracing of horseradish peroxidase (HRP) with the electron microscope using the tetramethylbenzidine reaction, J. Neurosci. Meth., 4 (1981) 373-383.

13 Sturmer, C., Bielenberg, K. and Spatz, B., Electron-microscopical identification of 3,3' $, 5,5^{\prime}$. tetramethylbenzidine reacted horseradish peroxidase after retrograde axoplasmic transport, Neurosci. Lett., 23 (1981) 1-6. 